\title{
Inhalt des 1. Bandes
}

Zeitungslehre und allgemeine Publizistik . . . . . . . . 5

Die Zeitung im öffentlichen Leben . . . . . . . . . . . 6

I. Die Einheit des Zeitungsunternehmens. . . . . . . 7

1. Einheit der Kräfte . . . . . . . . . . . . . . 7

a) Jüngstes Gegenwartsgeschehen . . . . . . . . . . 8

b) Kürzeste regelmäßige Folge . . . . . . . . . . . . 10

c) Breiteste Offentlichkeir . . . . . . 11

d) Die drei Hauptaufgaben und ihre Vereinigung . . . . . 16

2. Die öffentliche Aufgabe - die publizistische Durchführung . ， 20

3. Die journalistische (redaktionelie) Arbeit . . . . . 24

4. Die persönlichen Vorausserzungen der journalistischen Arbeit . . 30

5. Die verlegerische Arbeit . . . . . . . . 45

6. Charakter- und Begabungsvoraussetzungen des Verlegerberufes . 48

7. Die Zusammenarbeit Verleger - Redakteur . . . . . 50

II. Die Nachricht . . . . . . . . . . . . . . . . . . 54

1. Das Wesen der Nachricht . . . . . . . . . . 54

a) Wert und Nutzen für den Empfänger . . . . . . . . 55

b) Die Schnelligkeit der Ubermittlung . . . . . . . . . . 58

c) Subjektive Beeinflussung . . . : : . . . . . . . 59

2. Sammlung und Verbreitung der Nachrictien

Die Nachridntenbüros . . . . . . . . . . . . . . . . 64

a) Das deursche Nachrichtenwesen : . . . . . . . . . . 68

1. Die deutschen Presse-Agenturen : : : . . : . 68

2. Andere deutsche Nachrichtenbüros ....... 73

b) Das ausländische Nachrichtenweser

1. Reuters Ltd. . . . . . . . . . . . 76

2. Die nordamerikanischen Agenturen : . . . . . . . 78

3. Die französischen Nachrichtenagenturen . . . . . . 80

4. Die übrigen freien Agenturen . . : : : : 83

5. Das Nachrichtenbüro der UdSSR

c) Zusammenfassung - Vorschläge der "Vereinten Nationen" (UN) . . . . . . . 86

d) Die wichtigsten Nachrichtenunternehmen der Welt . : . : : 88

e) Die "Ente" - Das "Dementi" . . . . . . . . . . . . 93

f) Die Nachrichtenmitrel . . . : : : : . . : :95

3. Die Nachrichtenpolitik . . . . . . . . . . . . . 98

a) Nachrichrenstellen, Pressesteilen und -ämrer . . . . . . . 98

b) Die Nadrichtenpolitik der Interessenten - . . . 103

III. Die Meinungs- und Willensbildung in der Zeitung . . 105

1. Meinung, "öffentliche Meinung" und politische Willensbildung . 105

2. Die Form der Meinungsführung . . . . . . . . . . . . 113

a) Die Sprache in der Zeitung . . . . . . . . . . . . . 113

b) Die Formen des journalistischen Ausdrudks : . : . . . . . 119

1. Die Nachridtenstilform . . . . . . . . . . 120

2. Die Meinungsstilform. . . . : : : : : . . 124

3. Die Unterhaltungsstilform . . . . . . . . . . . . 132

c) Die Lern-und Lehrbarkeit des Stils : : : : : : : : : : 133

Literatur . . . . . . . . . . . . . 138

Register. . . . . . . . . . . . . . . 144 


\section{Inhalt des 2. Bandes}

IV. Die Redaktion . . . . . . . . . . . . . . 5

1. Ihr Aufbau . . . . . . . . . . . . . . . . . . 5

2. Die redaktionelle Arbeit im einzelnen . . . . . . . . . 10

3. Die Stoffbeschaffung . . . . . . . . . . . . . . . . 14

a) Der eigenbeschaffte Stoff . . . . . . . . . . . . . . 15

b) Der fremdbeschaffte Stoff - Die Korrespondenzen . . . . 22

I. Redaktionsgemeinschafter . . . . . . . . . . . 30

II. Anzeigengemeinschaften . . . . . . . . . . . . 31

III. Regionale Blätter mit Bezirkszeitungssystemen . . . . 32

4. Die Stoffbearbeitung, die redaktionellen Sparten (Ressorts) . . . 33

a) Die Politik . . . . . . . . . . . . . . . . . 36

b) Der "Handelsteil“, der Volkswirtschafliche Teil.", die Sozialpolitik................. . . 43

c) Der Orts- und Heimatteil . . . . . . . . . . . . . 48

d) Der kulturelle Teil und seine publizistisde Wertung. Das
Feuilleton - Der Feuilletonismus . 54

1. Kultur und Zeitung - Der Begriff "Feuilleton ". . . . 54

2. Das Feuilleton als Sparte... . . . . . . . . . 58

3. Der Feuilletonismus - Stilform und journalistische Haltung 82

e) Der Sportteil . . . . . . . . . . . . . . . . . . . 91

f) Die technische Redaktion . . . . . . . . . . . . . . . . . 93

g) Das Lichtbild - Die Bildberidhterstattung . . . . . . . 94

h) Umbruch und Aufmachung . . . . . . . . . . . . . . . . . 99

V. Die Technik und Wirtschaft im Zeitungsbetrieb . . . 104

1: Das Hauptbuch des Verlages . . . . . . . . . . 105

2. Die Ausgaben . . . . . . . . . . . . . . . . . . 107

a) Satz und Drudk . . . . . . . . . . . . . . . . . . 107

b) Papier . . . . . . . . . . . . . . . . . . . . . . 111

c) Vertrieb . . . . . . . . . . . . . . . . . . . 112

d) Die Kosten der Redaktion . . . . . . . . . . . . . . . 116

3. Die Einnahmen . . . . . . . . . . . . . . . . . . 119

a) Verkauf . . . . . . . . . . . . . . . . . . . . 119

b) Anzeigen . . . . . . . . . . . . . . . . . . . . . . . . . . 123

1. Die Anzeigenarten . . . . . . . . . . . . . . . 126

2. Zeitungsanzeigen als Werbemittel . . - . . . . . . . 127

3. Auflage und Anzeige. Die werbewirtschaftlichen Grundlagen 132

4. Textliche Fassung und graphische Form der Anzeige. . . 135

c) Einnahmen aus Nebenbetrieben. Zeitungsfremde Zuschüsse . . 137

4. Das Kostengesetz der Zeitung. Einnahmen und Ausgaben . . , . 138

5. Der Leser . . . . . . . . . . . . . . . . . . . . 144

VI. Die Sicherung des öffentlichen Auftrags . . . . . . . 149

Literatur . . . . . . . . . . . . . . . . 155

Register . . . . . . . . . . . . . . 163 